\title{
BMJ Open Protection of pregnant women at work in Switzerland: practices, obstacles and resources. A mixed-methods study protocol
}

\author{
Peggy Krief,, ${ }^{1,2}$ Alessia Zellweger, ${ }^{1,2,3}$ Maria-Pia Politis Mercier, ${ }^{3}$ Brigitta Danuser, ${ }^{1,2}$ \\ Pascal Wild, ${ }^{1,2,4}$ Michela Zenoni, ${ }^{1,2}$ Isabelle Probst ${ }^{3}$
}

To cite: Krief $P$, Zellweger $A$, Politis Mercier M-P, et al. Protection of pregnant women at work in Switzerland: practices, obstacles and resources. A mixed-methods study protocol. BMJ Open 2018;8:e023532. doi:10.1136/ bmjopen-2018-023532

- Prepublication history for this paper is available online. To view these files, please visit the journal online (http://dx.doi. org/10.1136/bmjopen-2018023532).

Received 13 April 2018 Revised 26 April 2018 Accepted 3 May 2018
Check for updates

${ }^{1}$ Occupational Health, Institute for Work and Health (IST), Lausanne, Switzerland ${ }^{2}$ University of Lausanne and Geneva, Switzerland ${ }^{3}$ School of Health Sciences (HESAV), University of Applied Sciences and Arts Western Switzerland (HES-SO), Lausanne, Switzerland ${ }^{4}$ Scientific Management, INRS, Vandœuvre-lès-Nancy, France

Correspondence to

Dr Peggy Krief;

peggy.krief@chuv.ch

\section{ABSTRACT}

Introduction Like most industrialised countries, Switzerland has introduced legislation to protect the health of pregnant workers and their unborn children from workplace exposure. This legislation provides for a risk assessment, adaptations to workplaces and, if the danger is not eliminated, preventive leave (prescribed by a gynaecologist). This study's first objective is to analyse the degree to which companies, gynaecologists and midwives implement the law. Its second objective is to understand the obstacles and resources of this implementation, with a focus on how relevant stakeholders perceive protective measures and their involvement with them.

Methods and analysis Data will be collected using mixed methods: (1) online questionnaires for gynaecologists and midwives; telephone questionnaires with company human resources (HR) managers in the healthcare and food production sectors; (2a) case studies of 6-8 companies in each sector, including interviews with stakeholders such as women workers, HR managers and occupational health physicians; (2b) two focus groups, one involving occupational physicians and hygienists, one involving labour inspectors. Quantitative data will be analysed statistically using STATA software V.15. Qualitative data will be transcribed and thematically analysed using MaxQDA software.

Ethics and dissemination The Human Research Ethics Committee of the Canton Vaud (CER-VD) has certified that this research study protocol falls outside of the field of application of the Swiss Federal Act on Research Involving Humans. The publications and recommendations resulting from this study will form the starting point for future improvements to the protection of pregnant women at work and their unborn children. This study started in February 2017 and will continue until January 2020.

\section{INTRODUCTION}

In Switzerland, as in the rest of the world, women represent a considerable proportion of the working population ( $46 \%$ in 2016, Swiss Federal Statistical Office). At $82.2 \%$, the country's proportion of women aged 25-54 years and in paid employment is one of the highest in Europe. ${ }^{1}$ Reconciling pregnancy and work
Strengths and limitations of this study

- A mixed-methods study provides insights into the underlying mechanisms of the implementation of maternity protection legislation.

- The experiences of multiple relevant stakeholders (gynaecologists, midwives, occupational physicians and hygienists, work inspectors, company representatives and women workers) will be taken into account.

- The study is limited to the French-speaking part of Switzerland, and the case studies include only two business sectors, such that results cannot be generalised to the overall situation in Switzerland.

- Certain categories of workers will not be interviewed, notably, temporary staff and women who left the company after giving birth.

is, therefore, more than merely a medical issue; it is an important economic challenge, too. Overall, the international medical literature shows that work in itself does not pose a risk to pregnancy. ${ }^{2-4}$ Nevertheless, certain specific professional activities ${ }^{25-9}$ can represent a risk to pregnancy and the unborn child, and these justify the introduction of legal provisions for the protection of maternity at work. ${ }^{10}$ Respecting those laws is of crucial importance to perinatal health. The maternity protection legislation (MPL) in place in most industrialised countries ${ }^{10}$ requires that occupational risks to pregnancy are assessed and measures are taken to avoid exposing pregnant workers to risks. This should primarily be done by eliminating those risks or adapting working conditions. If those options prove infeasible, employees should be transferred to another post or, as a last resort, granted paid leave.

\section{The protection of pregnancy at work in}

\section{Switzerland}

Switzerland's Labour Law, its ordinances and the Ordinance on Maternity Protection at 
Work (OProMa) set out which types of jobs are considered dangerous or arduous, the processes to be put in place to counter the risks and the responsibilities of all the actors involved. ${ }^{11}$

Employers are obliged to have an authorised specialist carry out an analysis of workstation risks before hiring women. This risk analysis must be communicated to the female employee and her immediate work supervisors.

Occupational physicians and hygienists or other authorised occupational health specialists must carry out risk analyses in order to minimise professional exposure to dangers via adaptations to workstations or changing job tasks. Those occupational health professionals then advise women workers, employers and other healthcare professionals.

It is the role of the treating physician (usually gynaecologist/obstetricians) to verify whether their patients are exposed to any professional activities banned under the OProMa. If they are, the risk analyses must be transferred to a doctor for a decision on whether the expectant mothers can safely continue employment at their workstations. In the absence of a risk analysis, but in the presence of presumed dangers, the doctor will issue a medical certificate of incapacity (preventive leave) according to the precautionary principle. Preventive leave is financed by employers until they remedy the dangerous situation in the workplace. The medical certificate of incapacity is different from sick leave, which is financed either directly by the employer or by the employer's loss of income insurance. $^{12}$

\section{Establishing a disparity between legislative provisions and the} reality in the workplace

International literature, ${ }^{13-16}$ exploratory studies in Switzerland ${ }^{17}$ and the project authors' personal experiences ${ }^{18}$ have highlighted several deficiencies in the implementation of the country's MPL: (1) stakeholders' lack of understanding about the risks and the legal provisions in place (employers, gynaecologists and, especially, expectant mothers); (2) cases where neither risk analyses nor workstation adaptations are made; and (3) the use of sick leave certificates in place than preventive leave. The latter practice weakens the law as an incentive for companies to develop internal preventive strategies. Similar findings were also highlighted by the authors in a recent international literature review, ${ }^{19}$ inspired by Bronfenbrenner's ecological model ${ }^{20}$ and realist approaches, ${ }^{21}$ which revealed the many levels of difficulty and complexity in introducing MPL: (1) the lack of knowledge about the legal provisions concerning occupational maternity protection, on the part of employees as well as employers, can have an impact on the implementation of appropriate measures; (2) at the organisational and social levels, the company's status, the collaboration between the different stakeholders and the way in which the notion of risk is defined within a company also play a role; and (3) at the societal level, the implementation of MPL depends largely on political incentives, the standing which women have in their company and knowledge about professional risks.

Thus, we hypothesised that the difficulties inherent in applying MPL were not only the result of women workers', employers' and healthcare professionals' lack of information, but we also supposed that these difficulties were linked to the complex and partially contradictory requirements of reconciling work and maternity, ${ }^{22}$ which encourage different actors to develop practices outside of the existing legal framework.

\section{METHODS AND ANALYSIS \\ Study aims}

This project aims to understand how MPL is applied within French-speaking Switzerland's companies and the components of its healthcare system and how it is perceived by the stakeholders concerned, particularly pregnant women. By identifying the obstacles and resources of current instruments and practices, the study will form a starting point for work to improve the health protection of pregnant workers and their unborn children. The research questions which will guide the present project are shown in table 1.

\section{Study design}

Choice of study design

With a view to getting the best overall picture of the situation, we plan to mix quantitative and qualitative approaches.

The quantitative part's goal is to evaluate the extent to which MPL is applied and to identify the principal factors which impede or facilitate the implementation of its measures. Questionnaires will be sent to companies in the healthcare and food industry sectors and to healthcare professionals in French-speaking Switzerland.

The qualitative part's goal is to understand the means by which different actors appropriate or translate the provisions of MPL and the reasons why companies act the way they do with regard to maternity. Case studies will be made of 6-8 companies per sector, including qualitative interviews with diverse stakeholders and, notably, human resources (HR) managers, occupational health and safety specialists and women workers (approximately 50 interviews in total). Two focus groups will be organised, one with occupational health professionals (occupational physicians and hygienists) and another with work inspectors.

The mixed methods design is the result of the current state of knowledge on this subject: the absence of data on the implementation of MPL makes it necessary to establish the law's current usage and identify the factors underlying the implementation of MPL, using questionnaires, whereas the case studies and focus groups are needed to understand the reasons at the origins of current company practices as well as different actors' representations. The combination and integration of both parts of the study will help us to understand how complex the implementation 


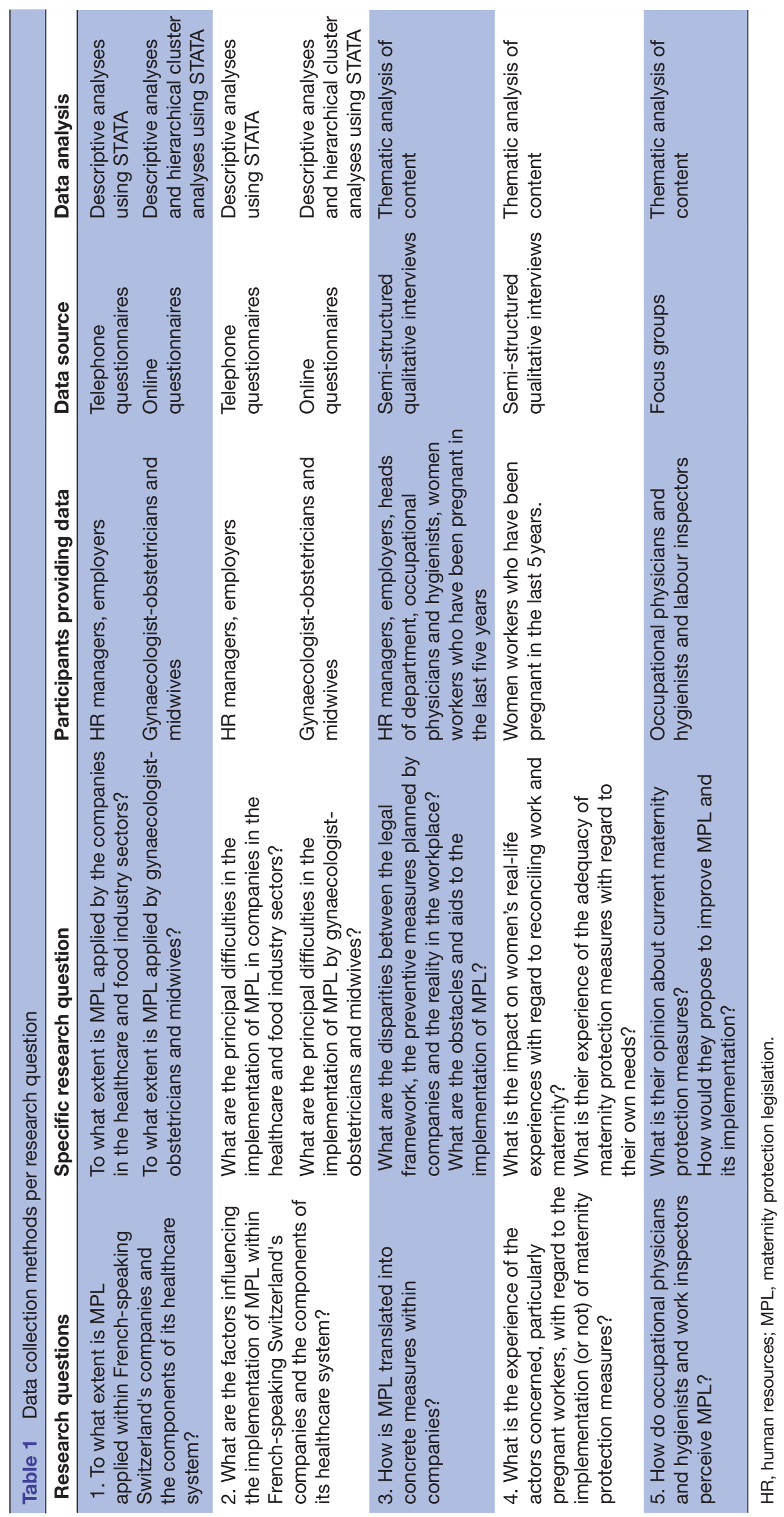


of these legal protection measures is, as well as what the current problematic aspects of the provisions are. ${ }^{23}$

\section{Field of study}

This study only has the means to look at Switzerland's six French-speaking cantons. With regard to the companies involved, the quantitative and qualitative parts of the study will also have to be restricted to the food industry and healthcare sectors (respectively, divisions 10 and 86 of the General Classification of Economic Activities (NOGA), Swiss Federal Statistical Office). These two sectors were selected in order to focus solely on activities where pregnant workers are especially at risk and therefore require the implementation of MPL. Furthermore, they employ a large number of female workers, which allows us to acquire a realistic sample for a telephone survey. This selection also provides to receive the support of the employers' associations concerned so as to encourage a good reception for the questionnaire and the company case studies (feasibility). The two sectors were chosen because they can involve exposure to factors, which are a risk to maternity, and they employ significant numbers of women. In Switzerland in 2015, women made up 44.3\% of the workforce in the food industry (NOGA 10) and $76.4 \%$ in the healthcare sector (NOGA 86) ${ }^{24}$ They were also chosen because of their economic differences (industrial vs service sector; uniquely private vs partially public), the types of jobs involved (manual or technical work in the food industry vs a wide range of healthcare jobs) and the sociodemographic profiles of the employees.

\section{Quantitative methodology}

\section{Sample selection and data collection}

The questionnaire for companies will be carried out by telephone on a sample of 200 companies distinguished by economic sector and size. The sample will be chosen at random from the Business and Enterprise Register by the Swiss Federal Statistical Office. An appointment will be made with a competent person within the organisation to answer the questionnaire. This telephone interview should be completed within $20 \mathrm{~min}$. The expected success rate for this operation is $25 \%$, which implies that the initial sample will have to comprise 800 companies.

The questionnaire for gynaecologist-obstetricians and midwives will be sent out via email to all of Frenchspeaking Switzerland's specialist gynaecologists-obstetricians, to doctors undergoing their specialisation and to members of the Swiss Federation of Midwives (FSSF), whether they work in hospital environments or private practice. Around 400 specialists (Swiss Medical Association statistics, 2013) will be contacted via the Swiss Gynaecology and Obstetrics Association and its cantonal chapters; around 600 midwives (FSSF statistics, 2013) will be contacted via the FSSF. The expected response rate of gynaecologists and midwives is around $30 \%$. Although midwives are not included in the OProMa, it is essential to involve them in the study because they carry out many maternity-related consultations, notably in maternity wards. It will be crucial to know whether they investigate any potential occupational risks to maternity and if they then refer the future mother to a gynaecologist or an occupational physician if they suspect any danger to her or her unborn child.

Online questionnaires have been selected because, in the investigators' experience, healthcare professionals are more likely to respond to online questionnaires they find in the email inboxes. This is different with companies, however. The telephone survey will allow us to get a better rate and more accuracy than a written questionnaire.

\section{Questionnaires}

The questionnaires include 31 questions for physicians and 30 for midwives, with 31 in the questionnaire for companies. The questions have been designed based on national and international literature and on the expertise of the project's research team. A test phase is planned for all three questionnaires.

\section{Data collection}

Questions for all the questionnaires were generated using Sphinx online software (V.4.8).

\section{Statistical analyses}

Data from the questionnaires' responses will be extracted into an Excel spreadsheet format and will be treated using STATA V.14 software.

Statistical analysis of the responses to the questionnaires from healthcare professionals will involve several stages:

- Simple descriptive and correlational statistics on all the items recovered, including associations, will be tested using Fisher's exact test.

- Multivariate and hierarchical cluster analyses. This analysis aims to generate hierarchical clusters (or typologies), from the variables describing healthcare professionals' practices on the one hand and from the variables describing their attitudes vis-à-vis legal provisions on the other. The objective is to identify the typologies of practice and attitudes by grouping together subjects who gave similar responses.

- Association between clusters (or typologies) of practice and attitudes: is one type of attitude associated with a particular type of practice?

With regard to the data from the questionnaires answered by company representatives, the statistical analysis will proceed as follows:

- Simple descriptive and correlational statistics on all the items recovered, including associations, will be tested using Fisher's exact test.

- For the questionnaires aimed at companies, all the analyses will take into account the initial stratification-food industry and healthcare sector-and will enable an estimation (using survey methods) of the number of women from these two economic sectors for whom MPL is not applied. 


\section{Statistical power}

For the questionnaire answered by companies, we target an effective sample group of 200 companies. This sample size will enable us to show a $15 \%$ difference in the implementation of MPL between the two groups, with a statistical power of $80 \%$ at the standard statistical significance threshold of $\mathrm{p}=0.05$.

Because the whole population of relevant healthcare professionals will be targeted and sent the questionnaire, this criterion is not relevant.

\section{Qualitative methodology}

We will integrate theory of activity approaches, as developed in the fields of sociocultural psychology 2526 and ergonomics, ${ }^{27}$ in order to make a fine-grained analysis of actors' practices. We always consider maternity protection to be more than the mere implementation of the relevant legal provisions and the resulting application of certain safety measures; rather, maternity protection should always be the result of the contextualised and collective action of all the actors concerned. This activity or action may imply a reconfiguration or translation of the planned measures in function of the perceived challenges, the constraints encountered and the available resources, and also of the dynamics emerging from the interactions in the workplace. ${ }^{28}$

\section{Case studies}

\section{Domains}

Case studies will be made on 6-8 different-sized companies from each of the two industrial sectors chosen for the project: healthcare and the food industry. Table 2 shows the number of companies that have been selected for the case studies.

In order to find case study participants, we will ask each company contacted and asked to complete a questionnaire, whether they would agree to take part in the qualitative part of the study.

\section{Data}

Data will be collected from the semistructured qualitative interviews with the principal actors involved in maternity protection in participating companies: (1) workers who have been pregnant at work within the last 5 years; (2) HR managers, employers and heads of department; (3) occupational physicians or occupational safety specialists; (4) other actors in the company who are involved in the implementation of MPL (eg, occupational health nurses, social workers, staff or union representatives). Table 3

\begin{tabular}{llll}
\hline Table 2 & \multicolumn{3}{l}{ Selection of companies for case studies } \\
\hline & $\begin{array}{l}\text { Small } \\
\text { (<50FTP) }\end{array}$ & $\begin{array}{l}\text { Medium } \\
\text { (50-250 FTP) }\end{array}$ & $\begin{array}{l}\text { Large } \\
\text { (>250 FTP) }\end{array}$ \\
\hline Healthcare & 1 & one or 2 & 1 \\
Food industry & 1 & one or 2 & 1 \\
\hline
\end{tabular}

FTP, full-time employees.

\begin{tabular}{|c|c|c|}
\hline Actors & $\begin{array}{l}\text { Number of } \\
\text { interviews } \\
\text { per company } \\
\text { (according to } \\
\text { size) }\end{array}$ & $\begin{array}{l}\text { Total estimated } \\
\text { for the } 6-8 \\
\text { companies }\end{array}$ \\
\hline Women workers & $1-6$ & $30-35$ \\
\hline HR managers & 1 & $6-8$ \\
\hline $\begin{array}{l}\text { Occupational } \\
\text { physicians and } \\
\text { hygienists }\end{array}$ & 1 & $6-8$ \\
\hline $\begin{array}{l}\text { Other relevant } \\
\text { actors }\end{array}$ & 0 or 1 & $4-5$ \\
\hline Total & & $46-56$ \\
\hline
\end{tabular}

HR, human resources.

resumes the number of interviews involved in each case study.

\section{Interview contents}

Interviews will last between $45 \mathrm{~min}$ and 1 hour. Six exploratory interviews have been carried out with workers who had once been employed during their pregnancies.

Table 4 describes the principal contents which will be covered with the different actors during the interviews.

\section{Focus groups}

\section{Domains}

In order to get expert opinions, we will organise focus group sessions with occupational health professionals (occupational physicians and hygienists) and work inspectors. These professionals were chosen because of their central role in the protection of health at work. The two focus groups will each be made up of 7-8 participants.

\section{Focus group contents}

Focus groups will last about 2 hours. Discussions between the participants will be sparked by the findings from the quantitative part of the study as well as questions examining participants' experience and their proposals for promoting maternity protection.

\section{Thematic analysis of the interviews and focus groups}

Interviews and focus groups will be respectively audio and video recorded, and their transcripts will be written out verbatim. In transcripts, participants' names will be substituted with a pseudonym, and any personal references which might enable identification of one of the participants will be erased. A thematic analysis will be undertaken to identify all the key categories and themes which emerge from the interviews. Segments of discourse will be coded using MaxQDA software in order to systematically treat passages referring to different themes. ${ }^{29}$ Any inter-rater disagreement as to which codes should be applied to which segments will be resolved by consensus among the research team. This activity is, therefore, 
Table 4 Principal themes to be brought up with the different actors

\begin{tabular}{|c|c|}
\hline Actors & Operationalisation \\
\hline $\begin{array}{l}\text { HR managers, } \\
\text { employers, heads of } \\
\text { department }\end{array}$ & $\begin{array}{l}\text { Number and categories of workers concerned by MPL in the past } 5 \text { years. } \\
\text { Types of risks or dangerous activities encountered by pregnant employees. } \\
\text { Information given to the employee. Measures put in place to encourage the employee to announce } \\
\text { her pregnancy. } \\
\text { Risk analyses and measures put in place following an employee's announcement of her pregnancy } \\
\text { (workplace adaptations, changing job tasks). } \\
\text { Collaboration with other professionals. } \\
\text { Difficulties met and resources available. } \\
\text { Incorporation into company policies and links to health protection in general. } \\
\text { Propositions and perspectives. }\end{array}$ \\
\hline $\begin{array}{l}\text { Women workers who } \\
\text { have been pregnant } \\
\text { in the company in the } \\
\text { last } 5 \text { years. }\end{array}$ & $\begin{array}{l}\text { The woman's experience with regard to her pregnancy in an occupational setting (start of } \\
\text { pregnancy, announcement to superiors, etc). } \\
\text { Information received on MPL. } \\
\text { Perception of the risk linked to work or arduous tasks. } \\
\text { Adaptations put in place by the company and the perceived level of adequacy with the woman's } \\
\text { needs. } \\
\text { Difficulties encountered in the protection of maternity in relation to work organisation, working } \\
\text { relationships, the job itself, etc. } \\
\text { Reduced working hours or exclusion from work. } \\
\text { Adaptations put in place by the woman. }\end{array}$ \\
\hline
\end{tabular}

HR, human resources; MPL, maternity protection legislation.

a co-construction of knowledge, whose goal is to help knowledge from these different domains emerge using an inductive approach. ${ }^{29}$

\section{Patients and public involvement}

Patients will not be involved in the study. If desired, the results of the study will be forwarded to the participants.

\section{Steering committee}

A steering committee will be made up of a dozen representatives from among the actors most concerned by maternity protection. The committee will meet every year throughout the project in order to facilitate investigations in the field, discuss results, sketch out recommendations and encourage the dissemination and use of the results.

\section{ETHICS AND DISSEMINATION}

\section{Ethical and safety considerations}

The Human Research Ethics Committee of the Canton Vaud (CER-VD) has certified that this research study protocol falls outside of the field of application of the Swiss Federal Act on Research Involving Humans because it will not collect 'personal health data'. The research team members have made sure that the study respects the following ethical principles: all the personal data gathered will be treated confidentially; questionnaire, interview and focus group participants will be anonymised; written informed consent will be requested from all the interview and focus group participants; data will be securely stored; and the data will only be used for research purposes. Participation in this research study will be voluntary. In the hypothetical case where, during an interview, an employee reveals the existence of a working environment which might be dangerous for her health or that of her colleagues, the research team will suggest that she contacts the Institute for Work and Health.

Data privacy will be guaranteed: all the research data gathered during the project will be treated confidentially; non-anonymised data will be kept under lock and key (video and audio recordings, written informed consent forms and questionnaires, coding lists); anonymisation of interview transcripts (names and companies); persons interviewed and companies will be identified using pseudonyms; and communications and publications will not enable identification of individuals or companies.

With a view to equity, the case studies will cover unskilled workers, short fixed-term contract or casual workers, and workers from disadvantaged social groups. These types of employees are more often subject to harmful working conditions $^{30}$ and are frequently under-represented in surveys. We will thus notably attempt to include non-Francophone workers by offering translation. Temporary staff and women who have since left participating companies will not be interviewed. These two categories of workers are, however, more likely to experience difficulties than full-time employees. The analysis of the case studies will take these limitations into account.

\section{Dissemination}

\section{Articles}

We plan to publish 4-5 main articles in peer-reviewed scientific journals; we will also publish several articles in professional journals, and we will communicate our results in congresses covering a variety of disciplines. 
This significant research project will also result in a PhD thesis.

\section{Training}

Because the research team is directly involved in training gynaecologists, midwives, occupational physicians and occupational health nurses, the project's conclusions will be directly transferable to teaching (implementation of the legal provisions on maternity protection, the consideration of work-related issues and the dispensation of relevant advice during pregnancy monitoring). At the end of the research project, a day's training workshop will be organised for professionals and institutions involved in the field of maternal health, to both disseminate results and debate possible improvements to maternity protection and the legislation covering it.

\section{Recommendations}

This project will enable the design of recommendations to raise the awareness of all the stakeholders in the field of maternity protection (including the general public and the public authorities) about the occupational risks to maternity and the need to improve preventive measure in this area.

By objectifying the degree of implementation of the legal provisions on maternity protection, as well as their deficiencies, this project will encourage a revision of the relative legal instruments and the design of new strategies by organisations which have to execute them. This will optimise the implementation of legal provisions and ensure greater maternity protection at work across Switzerland.

The project could also bring into question the current attribution of roles made by the OProMa. For example, this could be by entrusting the job of giving an opinion on a pregnant employee's aptitude or inaptitude to work to occupational physicians because of their specialist training which is at the interface between the worlds of work and health. It could also be by taking into account the fact that some pregnancies are only ever monitored by midwives.

\section{Perspectives}

Thanks to its combination of sources of information, from companies, workers and healthcare professionals, this research project will provide objective data that have never before been gathered on the implementation of MPL in Switzerland. This will also enable comparisons with the policies in other countries. The project's quantitative and qualitative mixed-methods design aims to provide a significant contribution to our knowledge about maternal health protection in Switzerland in the face of occupational risks. Indeed, previous research has repeatedly shown the gaps between recommended levels of protection for workers and those which are in fact implemented in occupational settings. There is consequently a need to understand the reasons and determining factors for actors' practices in particular occupational situations, ${ }^{2631-33}$ in this case, maternity.
Contributors The principal investigator, IP, the two coinvestigators, PK and BD, and the senior scientific collaborator, M-PP-M, jointly designed this research protocol. PK is the first author of this article. PW, a statistician, supported the development of the methodology and he will assist the statistical analysis of quantitative data. PhD candidate $\mathrm{AZ}$ and junior scientific collaborator MZ participated in the drafting of this protocol.

Funding This work is supported by the Swiss National Science Foundation (grant number 162713), by Canton Vaud's Public Health Service and by a research fund belonging to the University of Applied Sciences and Arts Western Switzerland (HESSO). The Institute for Work and Health (IST) and HES-SO's School of Health Sciences (HESAV) contribute to salaries.

Competing interests None declared.

Patient consent Not required.

Provenance and peer review Not commissioned; peer reviewed for ethical and funding approval prior to submission.

Data sharing statement Questionnaires and interview guides are available on request.

Open access This is an open access article distributed in accordance with the Creative Commons Attribution Non Commercial (CC BY-NC 4.0) license, which permits others to distribute, remix, adapt, build upon this work non-commercially, and license their derivative works on different terms, provided the original work is properly cited and the use is non-commercial. See: http://creativecommons.org/ licenses/by-nc/4.0/

(c) Article author(s) (or their employer(s) unless otherwise stated in the text of the article) 2018. All rights reserved. No commercial use is permitted unless otherwise expressly granted.

\section{REFERENCES}

1. Giudici F, Schumacher R. Le travail des mères en Suisse: évolution et déterminants individuels. Social Change in Switzerland 2017.

2. Casas M, Cordier S, Martínez D, et al. Maternal occupation during pregnancy, birth weight, and length of gestation: combined analysis of 13 European birth cohorts. Scand J Work Environ Health 2015;41:384-96.

3. Fowler JR, Culpepper L. Working during pregnancy, 2018.

4. Palmer KT, Bonzini M, Bonde JP. Pregnancy: occupational aspects of management: concise guidance. Clin Med 2013;13:75-9.

5. Goldman RH, Wylie JB. Overview of occupational and environmental risks to reproduction in females. 2017 https://www.uptodate.com/ contents/overview-of-occupational-and-environmental-risks-toreproduction-in-females.

6. Bilhartz TD, Bilhartz P. Occupation as a risk factor for hypertensive disorders of pregnancy. J Womens Health 2013;22:188a-188i.

7. Figà-Talamanca I. Occupational risk factors and reproductive health of women. Occup Med 2006;56:521-31.

8. Grossesse et travail: quels sont les risques pour I'. Lafon D, ed. enfant à naître? EDP Sciences ed. Les Ulis: Institut National de recherche et de Sécurité (INRS), 2010.

9. Stocker LJ, Macklon NS, Cheong YC, et al. Influence of shift work on early reproductive outcomes: a systematic review and meta-analysis. Obstet Gynecol 2014;124:99-110.

10. International Labour Organization. Maternity at Work: A Review of National Legislation: Findings From The ILO Database of Conditions of Work and Employment Laws. Geneva, 2010.

11. International Labour Organization. Switzerland - Maternity protection - 2011: TRAVAIL Legal Database, 2011.

12. Krief $P$, Schreyer $A$. Inaptitude ou incapacité de travail de la travailleuse enceinte par le gynécologue. Une ordonnance que tout médecin de la spécialité doit prendre en considération et que tout médecin généraliste doit connaitre: Courrier du médecin vaudois, 2015.

13. Makowiec-Dabrowska T, Hanke W, Radwan-Włodarczyk Z, et al. [Working condition of pregnant women. Departures from regulation on occupations especially noxious or hazardous to women]. Med $\mathrm{Pr}$ 2003;54:33-43.

14. Lembrechts $L$, Valgaeren $E$, travail $G$. Le vécu et les obstacles rencontrés par les travailleuses en Belgique. Etude quantitative et qualitative: Bruxelles: Institut pour l'égalité des femmes et des hommes, 2010.

15. Adams L, Winterbotham M, Oldfield K, et al. Pregnancy and Maternity-Related Discrimination and Disadvantage: Experiences of Mothers. London: Department for Business, Innovation and Skills, Equality and Human Rights Commission, 2016. 
16. Adams L, Winterbotham M, Oldfield K, et al. Pregnancy and Maternity-Related Discrimination and Disadvantage. London: Department for Business, Innovation and Skills, 2016.

17. Aellen G, Nicollier L, Outdili Z, et al. Application de l'Ordonnance sur la protection de la maternité chez les femmes médecins. Revue médicale suisse 2013;393:1433-4.

18. Grolimund Berset D, Krief P, Praz-Christinaz SM. Difficultés pratiques de la mise en application de l'Ordonnance sur la protection de la maternité (Oproma) en Suisse à la lumière de deux cas cliniques. Archives des Maladies Professionnelles et de l'Environnement 2012;73:524-5.

19. Probst I, Zellweger A, Politis Mercier M-P, et al. Implementation, mechanisms, and effects of maternity protection legislation: a realist narrative review of the literature. Under review.

20. Story M, Kaphingst KM, Robinson-O'Brien R, et al. Creating healthy food and eating environments: policy and environmental approaches. Annu Rev Public Health 2008;29:253-72.

21. Pawson R, Greenhalgh T, Harvey G, et al. Realist review--a new method of systematic review designed for complex policy interventions. J Health Serv Res Policy 2005;10:21-34.

22. Malenfant $\mathrm{R}$, De Koninck M. Production and reproduction: the issues involved in reconciling work and pregnancy. NEW SOLUTIONS: A Journal of Environmental and Occupational Health Policy 2002;12:61-77.

23. Guetterman TC, Fetters MD, Creswell JW. Integrating Quantitative and Qualitative Results in Health Science Mixed Methods Research Through Joint Displays. Ann Fam Med 2015;13:554-61.
24. Office FS. Etablissements et emplois selon le canton, la division économique et la classe de taille, 2015.

25. Engeström Y. Developmental Work Research: Expanding Activity Theory in Practice. Berlin: Lehmanns, 2005.

26. Clot Y, Faïta D. Genres et styles en analyse du travail Concepts et méthodes. Travailler 2000;4:7-42.

27. Daniellou * $F$. The French-speaking ergonomists' approach to work activity: cross-influences of field intervention and conceptual models. Theoretical Issues in Ergonomics Science 2005;6:409-27.

28. Probst I, Grossen M, Perret J-F. De la conception à la pratique: configuration et reconfiguration d'un dispositif de formation des enseignants aux technologies de l'information et de la communication. Revue Suisse des Sciences de l'Education 2007;29:453-72.

29. Braun V, Clarke V. Using thematic analysis in psychology. Qual Res Psychol 2006;3:77-101.

30. Landsbergis PA, Grzywacz JG, LaMontagne AD. Work organization, job insecurity, and occupational health disparities. Am J Ind Med 2014;57:495-515.

31. Mias A, Legrand E, Carricaburu D, et al; Le travail de prévention. Les relations professionnelles face aux risques cancérogènes. Toulouse: Octarès, 2013.

32. Cru $\mathrm{D}$, règle Lrisqueetla. Le cas du bâtiment et des travaux publics. Toulouse: Erès, 2014.

33. Laberge M, MacEachen E, Calvet B. Why are occupational health and safety training approaches not effective? Understanding young worker learning processes using an ergonomic lens. Saf Sci 2014;68:250-7. 